\title{
Clostridium difficile and inflammatory bowel disease
}

\author{
C GREENFIELD, J R AGUILAR RAMIREZ, R E POUNDER, T WILLIAMS, \\ M DANVERS, S R MARPER, AND P NOONE
}

\begin{abstract}
From the Academic Department of Medicine and Department of Medical Microbiology, Royal Free Hospital School of Medicine, London
\end{abstract}

SUMMARY Stools from 109 patients with inflammatory bowel disease $(13.4 \%)$ contained Clostridium difficile or its toxin, an incidence similar to the stools of 99 control patients with diarrhoea $(11.9 \%)$, but significantly higher than the stools of 77 control patients with a normal bowel habit $(1.4 \%)$. Sixty-six per cent of the diarrhoea controls, but only $11 \%$ of the inflammatory bowel disease patients, reported recent antibiotic use: however, $67 \%$ of inflammatory bowel disease patients were taking sulphasalazine. The presence of $\mathrm{Cl}$ difficile in the stool was not related to the clinical assessment of inflammatory bowel disease relapse, but it was related to hospital admission. During the one year study, 31 of the 109 patients $(28 \%)$ with inflammatory bowel disease had one or more stool samples that were positive for $\mathrm{Cl}$ difficile.

Recent studies have shown that a toxin of Clostridium difficile has a pathogenic role in patients with pseudomembranous colitis or antibiotic associated diarrhoea without pseudomembrane formation. ${ }^{1-3}$ Pseudomembranous colitis may occur without any predisposing factor; ${ }^{4}$ but there is some evidence that $\mathrm{Cl}$ difficile may be infectious. ${ }^{5-8}$

There are five reports ${ }^{9-13}$ concerning the identification of $\mathrm{Cl}$ difficile or its toxin in stools of patients with inflammatory bowel disease: three reports conclude that $\mathrm{Cl}$ difficile is found frequently in such patients, especially when there is active inflammation. ${ }^{-11}$

In the present study, stool samples from patients with inflammatory bowel disease have been compared with samples from two groups of control patients. The presence of $\mathrm{Cl}$ difficile or its toxin in a patient's stool has been correlated with recent exposure to antibiotics or sulphasalazine, activity of inflammatory bowel disease, and hospital admission.

\section{Methods}

PATIENTS WITH INFLAMMATORY BOWEL DISEASE From October 1980 to September 198167 patients with ulcerative colitis and 42 patients with Crohn's disease took part in the prospective study. The

Address for correspondence: Dr R E Pounder, Royal Free Hospital, Pond Street, London NW3 2QG.

Received for publication 11 October 1982 diagnosis of inflammatory bowel disease was based upon accepted clinical, radiological, and histological criteria.

Whenever a patient was seen as an outpatient, or approximately every week on the ward, a record was made of frequency of bowel actions, the patient's well-being (better, same, worse), the duration of clinical relapse, the presence of blood or mucus in the stool, and the drug therapy (including antibiotic use) during the preceding month. Physical examination included sigmoidoscopy. On the basis of this information, the physician assessed whether the patient's inflammatory bowel disease was in remission or relapse, and then treated the patient appropriately using a conventional combination of steroids, sulphasalazine, and occasionally azathioprine. No disease activity index was used. Blood samples were taken for haemoglobin, white count, ESR, and serum albumin. The clinicians were not informed of the stool analysis results for either $\mathrm{Cl}$ difficile or its toxin until the end of the study.

CONTROL PATIENTS WITH DIARRHOEA

One hundred and twenty-eight stool samples were obtained from 99 hospital inpatients with acute diarrhoea. Sixty-six per cent of these stool samples came from patients with a recent exposure to antibiotics. These clinical samples had been sent to the laboratory for routine $\mathrm{Cl}$ difficile analysis, as either pseudomembranous colitis or antibiotic associated diarrhoea was suspected. 
HEALTHY CONTROL PATIENTS

Seventy-seven stool samples came from hospital outpatients, who had attended the hospital for upper gastrointestinal endoscopy. All except one patient reported either normal bowel habit or constipation when these stool samples were collected. Seven samples were excluded: six patients had taken antibiotics in the preceding month and one had recently been an inpatient, and was receiving large doses of cimetidine, chlorpheniramine maleate, and hydroxyurea for systemic mastocytosis.

\section{CLOSTRIDIUM DIFFICILE CULTURE}

A selective medium (Oxoid Ltd, Basingstoke, Hampshire) consisting of an agar base, a selective supplement (containing D-cycloserine and cefoxitin) and 7\% defibrinated horse blood (Gibco, Europe) was used for the culture of $\mathrm{Cl}$ difficile from the stool samples. A light innoculum of the stool was spread over each plate and incubated in a Coy anaerobic chamber at $37^{\circ} \mathrm{C}$ for 48 hours. Plates were inspected under ultraviolet light and colonies showing a typical appearance were subcultured to obtain a pure growth of the organism. Identity of $\mathrm{Cl}$ difficile was confirmed by demonstration of characteristic patterns of fermentation of $1 \%$ carbohydrates incorporated in Fastidious Anaerobic Broth (London Analytical \& Bacteriological Media Ltd, Salford, Manchester M6 6PB). ${ }^{14}$

\section{CLOSTRIDIUM DIFFICILE TOXIN ASSAY}

Ringer's solution was added to stools for toxin assay to give a 1-in-4 dilution of liquid stools, and a 1-in-8 dilution of solid stools. The suspension was then centrifuged at $3000 \mathrm{~g}$ for 10 minutes, followed by $15000 \mathrm{~g}$ for 20 minutes and the supernatant passed through a $0.2 \mu \mathrm{m}$ membrane filter (Microflow 25, Flow Laboratories, Irvine, Scotland). Monolayers of MRC5 fibroblasts were prepared in microtitre trays with flat bottomed wells (Sterilin Ltd, Teddington, Middlesex). Stool filtrates were diluted 1-in-10 in tissue culture medium (Eagle's minimum essential medium with $2 \%$ fetal calf serum) and $0 \cdot 1$ $\mathrm{ml}$ of the dilution added to each of two microtitre wells. One well contained $0 \cdot 1 \mathrm{ml}$ of a 1 -in-10 dilution of $\mathrm{Cl}$ sordellii antitoxin (Wellcome Research Laboratories, Beckenham, Kent) in tissue culture medium and the other contained $0.1 \mathrm{ml}$ of tissue culture medium alone. The monolayers were examined for a cytopathic effect after five, 24 , and 48 hours' incubation at $37^{\circ} \mathrm{C}$. A clear, typical cytopathic effect in the well containing the stool filtrate alone, but not in its sister well which also contained antitoxin, was recorded as a positive toxin assay. ${ }^{15}$

STATISTICAL ANALYSIS

$\chi^{2}$ test, with no correction for continuity.

\section{Results}

During the year's study, 333 stool specimens were collected from patients with inflammatory bowel disease, an average of $3 \cdot 1$ specimens per patient (range 1-14). Patients were unable to provide a stool sample on 62 occasions. Approximately equal numbers of specimens were obtained from patients with ulcerative colitis during periods of remission and relapse (110 and 108 respectively), but more specimens were obtained from patients with Crohn's disease during the remission than relapse ( 71 and 43 , respectively).

Table 1 shows that $\mathrm{Cl}$ difficile and/or its toxin were found in $13.2 \%$ of stool samples from patients with Crohn's disease, in $13.7 \%$ of samples from patients with ulcerative colitis, and in $11.7 \%$ of samples from the inpatient controls with diarrhoea. As either culture of $\mathrm{Cl}$ difficile or detection of its toxin signifies the presence of the organism in a stool sample, the detection of either marker identified a stool sample as ' $\mathrm{Cl}$ difficile positive'. Only one sample from the healthy outpatient controls was positive for $\mathrm{Cl}$ difficile $(1.3 \%)$. .In all three (Crohn's disease, ulcerative colitis, and diarrhoea) groups, positive samples were significantly more frequent than in the healthy outpatient controls $(\mathrm{p}<0.01)$.

Table 2 shows that the incidence of $\mathrm{Cl}$ difficile

Table 1 Results of stool analysis for Cl difficile

Positive for Cl difficile

\begin{tabular}{|c|c|c|c|c|c|c|}
\hline & \multirow[b]{2}{*}{$\begin{array}{l}\text { No of } \\
\text { stools }\end{array}$} & \\
\hline & & $\begin{array}{l}\text { Toxin } \\
\text { only }\end{array}$ & $\begin{array}{l}\text { Culture } \\
\text { only }\end{array}$ & Both & Total & $\%$ \\
\hline Crohn's disease & 114 & 0 & 9 & 6 & 15 & $13 \cdot 2$ \\
\hline Ulcerative colitis & 219 & 4 & 14 & 12 & 30 & $13 \cdot 7$ \\
\hline Inpatient controls (diarrhoea) & 126 & 4 & 5 & 6 & 15 & 11.9 \\
\hline Outpatient controls (healthy) & 70 & 0 & 1 & 0 & 1 & 1.4 \\
\hline
\end{tabular}


Table 2 Stool samples from patients with inflammatory bowel disease

\begin{tabular}{|c|c|c|c|}
\hline \multirow[b]{2}{*}{ Clinical state } & \multirow{2}{*}{$\begin{array}{l}\text { No of } \\
\text { stools } \\
\text { analysed }\end{array}$} & \multicolumn{2}{|c|}{$\begin{array}{l}\text { Cl difficile } \\
\text { positive }\end{array}$} \\
\hline & & No & $\%$ \\
\hline Remission & 157 & 22 & 14 \\
\hline Relapse & 176 & 23 & 13 \\
\hline On antibiotics* & 36 & 11 & 31 \\
\hline On sulphasalazine ${ }^{*}$ & 224 & 30 & 13 \\
\hline \multicolumn{4}{|l|}{ No antibiotic or } \\
\hline sulphasalazine* & 73 & 4 & $5 \cdot 5$ \\
\hline
\end{tabular}

* Within last month.

positive stool samples was virtually identical during either clinical remission or relapse of inflammatory bowel disease (14\% and $13 \%$, respectively). Thirteen per cent of stool samples from patients taking only sulphasalazine were positive, but the history of antibiotic use during the preceding month significantly increased the incidence of positive samples to $31 \%(p<0.01)$. Antibiotics used by the patients were: amoxycillin, cefuroxime, dapsone, erythromycin, flucloxacillin, metronidazole, mezlocillin, rifampicin, co-trimoxazole, and oxytetracycline. Patients taking neither sulphasalazine nor antibiotics had $5.5 \%$ positive stools: although this was considerably lower than the incidence found in patients taking sulphasalazine alone, the difference is not statistically significant $(p<0 \cdot 1)$. Fifty-two per cent of the patients not taking either sulphasalazine or antibiotics were in remission, compared with $45 \%$ of the remaining inflammatory bowel disease patients: in neither subgroup did $\mathrm{Cl}$ difficile positive stool samples relate to disease activity.

The isolation of $\mathrm{Cl}$ difficile or its toxin from the stools was significantly related to hospital admission $(p<0.01)$. Twenty-four patients with inflammatory bowel disease were admitted to hospital during the year, 12 had one or more positive stools for $\mathrm{Cl}$ difficile. The other 19 patients with positive stools had no history of hospital admission during the study year. Of the patients admitted to hospital, four had a total colectomy, two had a hemicolectomy with a resection of the terminal ileum, and one died with colonic perforation. Five of the six patients requiring surgery had $\mathrm{Cl}$ difficile in their stool at some time, but these patients had all been exposed to recent antibiotics. There was no histological evidence of pseudomembranous colitis in the resected colonic material.

\section{Discussion}

$\mathrm{Cl}$ difficile is found frequently in the stools of patients with inflammatory bowel disease, without exposure to broad spectrum antibiotics. In the present study $13.4 \%$ of stools of patients with inflammatory bowel disease were $\mathrm{Cl}$ difficile positive, a result very similar to the $11.9 \%$ positive stools from one of this study's control groups (hospital inpatients with diarrhoea) and a study of diarrhoea after antibiotic treatment. ${ }^{16}$ The main difference between the two groups in this study was that whereas $66 \%$ of the diarrhoea control stools had been exposed recently to antibiotics, only $11 \%$ of the samples from the inflammatory bowel disease had been so exposed $(p<0 \cdot 01)$. Sixty-seven per cent of the inflammatory bowel disease stools, however, had been exposed to sulphasalazine, which is deconjugated in the colon, releasing free sulphapyridine in the stools. ${ }^{17}$

The patients with inflammatory bowel disease with a history of recent antibiotic exposure had a significantly higher incidence of $\mathrm{Cl}$ difficile in their stools than those taking only sulphasalazine $(31 \%$ against $13 \%$, respectively, $\mathrm{p}<0.01$ ). Stools from patients with inflammatory bowel disease taking neither antibiotics nor sulphasalazine, however, had an even lower incidence of $\mathrm{Cl}$ difficile $(5 \cdot 5 \%)$. This incidence of positive stools was not significantly different from the $1.3 \%$ found in the stools of the other control (outpatient) group, who had a normal bowel habit and no recent exposure to antibiotics.

Although it is suggested that the use of antibiotics facilitates the overgrowth of $\mathrm{Cl}$ difficile in the stool, ${ }^{18}$ the effects of sulphasalazine on the faecal flora are less certain. Early studies were contradictory, suggesting both a rise and a fall of anaerobes, ${ }^{1920}$ but a recent study reported no change in the anaerobic flora. ${ }^{21}$ The results of the present study suggest that sulphasalazine encourages the presence of $\mathrm{Cl}$ difficile in the stools of patients with inflammatory bowel disease, despite its undoubted beneficial effect in the prevention of inflammatory bowel disease relapse. ${ }^{22}$

Unlike earlier reports, ${ }^{9-11}$ the present prospective study does not show a relationship between the clinical assessment of inflammatory bowel disease activity and the presence of $\mathrm{Cl}$ difficile in the stool. $\mathrm{Cl}$ difficile, however, was significantly more frequent in the stools of those patients with inflammatory bowel disease admitted to hospital. It is remotely possible that these patients may have been infected by a contaminated hospital environment, ${ }^{57}$ and that there is no causal relationship between $\mathrm{Cl}$ difficile's presence and disease activity. Alternatively, as the results of $\mathrm{Cl}$ difficile isolation and the measurement of its cytotoxin are not always concordant for the same stool sample, ${ }^{18}{ }^{23}$ it is possible that stool analysis only detects a certain degree of faecal 
overgrowth with the organism. Indeed, in terms of the pathogenesis of colonic damage, these toxin assays are irrelevant, as the cytotoxin measured in this and most other studies is probably not the toxin that induces colitis. ${ }^{24}$ The combination of inexact clinical assessment of disease activity ${ }^{25}$ and imprecise detection of either $\mathrm{Cl}$ difficile or its non-pathogenic toxin, may have obscured any correlation between the two events, especially in outpatients with inflammatory bowel disease.

It is also possible that $\mathrm{Cl}$ difficile has no pathogenic role; its proliferation could be facilitated by either a damaged colonic mucosa or by liquid colonic contents during diarrhoea.

Symptomatic improvement of inflammatory bowel disease after uncontrolled vancomycin treatment has been cited as further evidence that $\mathrm{Cl}$ difficile may have a pathogenic role in inflammatory bowel disease. ${ }^{9}$. When the results of the present study were analysed at the end of the year, it was clear that two patients (one with ulcerative colitis and the other with Crohn's colitis) had persistently positive stool samples for $\mathrm{Cl}$ difficile. Both patients were ill with continuing colitis despite conventional treatment. They were treated with vancomycin 250 $\mathrm{mg}$ qds for 10 days. $\mathrm{Cl}$ difficile and its toxin were eradicated from their stools, but the patients' symptoms did not improve dramatically.

The results of the present study show that $\mathrm{Cl}$ difficile is found with an increased frequency in the stools of patients with inflammatory bowel disease, suggesting that it may be a cause of illness in some of these patients. $\mathrm{Cl}$ difficile was found in the stools of $28 \%$ of these patients on one or more occasions during the year. As the laboratory assessment of $\mathrm{Cl}$ difficile or its pathogenic toxin may be imprecise, it is possible that its role in inflammatory bowel disease may even have been underestimated by this study. Eradication of colonic $\mathrm{Cl}$ difficile may induce remission of colitis. This hypothesis could be tested by a placebo-controlled trial of oral vancomycin in patients with acute colitis in whom conventional laboratory assessment for $\mathrm{Cl}$ difficile is negative; a preliminary report of such a study suggests that vancomycin may be of benefit. ${ }^{26}$

Clostridia species are important veterinary pathogens, but are controlled by successful innoculation programmes. ${ }^{24}$ Similar immunisation in man proects against necrotising enterocolitis. ${ }^{28}$ Human immunisation using $\mathrm{Cl}$ difficile toxoid is feasible and would be a practical proposition in a high risk population: patients with inflammatory bowel disease may fulfil this role.

This study was supported by a grant from the Peter Samuel Royal Free Fund.
References

1 Bartlett JG. Antibiotic associated pseudomembranous colitis. Rev Infect Dis 1979; 1: 530-3.

2 Larson HE, Price AB, Honour P, Borriello SP. Clostridium difficile and aetiology of pseudomembranous colitis. Lancet 1978; 1: 1063-6.

3 Larson HE, Price AB. Pseudomembranous colitis: presence of Clostridial toxin. Lancet 1977; 2: 1312-4.

4 Howard JM, Sullivan SN, Troster M. Spontaneous pseudomembranous colitis. Br Med J 1980; 2: 356.

5 Greenfield C, Burroughs A, Szawathowski M, Bass N, Noone P, Pounder RE. Is pseudomembranous colitis infectious? Lancet 1981; 2: 371-2.

6 Larson HE, Price AB, Borriello SP. Epidemiology of experimental enterocolitis due to Clostridium difficile. J Infect Dis 1980; 142: 408-13.

7 Fekety R, Kim K, Silva J, Balts D, Cudmore M, Brown D. Epidemiology of antibiotic associated colitis: environmental contamination with $\mathrm{Cl}$ difficile. In: Abstracts ICAAC, New Orleans, 1980, No 202.

8 Larson HE. Pseudomembranous colitis is an infection. $J$ Infect Dis 1979; 1: 221-6.

9 La Mont JT, Trnka YM. Therapeutic implications of Clostridium difficile toxin during relapse of chronic inflammatory bowel disease. Lancet 1980; 1: 381-3.

10 Bolton RP, Sheriff RJ, Read AE. Clostridium difficile associated diarrhoea: a role in inflammatory bowel disease. Lancet 1980; 1: 383-4.

11 Trnka YM, La Mont JT. Association of Clostridium difficile toxin with symptomatic relapse of chronic inflammatory bowel disease. Gastroenterology 1981; 80: $693-6$.

12 Meyer S, Mayer L, Bottone E, Desmond E, Janowitz HD. Occurrence of Clostridium difficile toxin during the course of inflammatory bowel disease. Gastroenterology 1981; 80: 697-700.

13 Keighley MRB, Youngs D, Johnson M, Allan RN, Burdon DW. Cl difficile toxin in acute diarrhoea complicating inflammatory bowel disease. Gut 1982; 23: $410-4$.

14 Holdeman LV, Cato EP, Moore WEC. In: Anaerobic laboratory manual 4th ed. Blacksburg, Virginia: Virginia Polytechnic Institute and State University, 1977.

15 Chang TW, Laverman M, Bartlett J. Cytotoxicity assay in antibiotic associated colitis. J Infect Dis 1979; 140: 765-70.

16 Lishman AH, Al Jumaili IS, Record CO. Spectrum of antibiotic associated diarrhoea. Gut 1981; 22: 34-7.

17 Campbell DES. Possible modes of action of Salazopyrin. Z Gastroenterol 1981; 19: suppl: 14-19.

18 Barriello SP, Larson HE. Antibiotic and pseudomembranous colitis. J Antimicrob Chemother 1981; 7: suppl A: 53-62.

19 Cook EM. Faecal flora of patients with ulcerative colitis during treatment with salicylazosulphapyridine. Gut 1969; 19: 565-8.

20 West B, Lendrum R, Hill MJ, Walker G. Effect of sulphasalazine on faecal flora in patients with inflammatory bowel disease. Gut 1974; 15: 960-5. 
21 Krook A. Effect of metronidazole and sulphasalazine on the normal human faecal flora. Scand J Gastroenterol 1981; 16: 587-92.

22 Misiewicz JJ, Lennard-Jones JE, Connell AM, Baron $\mathrm{JH}$, Avery Jones F. Controlled trial of sulphasalazine in maintenance therapy for ulcerative colitis. Lancet 1965 ; 6: $185-8$.

23 Burdon DW, Thompson H, Candy DCA, Kearns M, Lees D, Stephen J. Enterotoxins of Clostridium difficile. Lancet 1981; 2: 258-9.

24 Taylor NS, Thorne GH, Barlett JG. Separation of an enterotoxin from the cytotoxin of Clostridium difficile. Clin Res 1980; 28: 285A.
25 Hodgson HJF. Assessment of drug therapy in inflammatory bowel disease. Br J Clin Pharmacol 1982; 14: 159-70.

26 Pinder IF, Hamilton I, Dickinson RT, O'Connor H, Johnston D, Axon ATR. Vancomycin as adjunctive therapy in acute exacerbations of idiopathic colitis. (Abstract.) Gut 1982; 23: A452-3.

27 Sterne M, Batty I, Thompson A, Robertson JM. Immunization of sheep with multi-component Clostridial vaccines. Vet Rec 1962; 74: 909-13.

28 Lawrence G, Shann F, Freestone DS, Walker PD. Prevention of necrotising enteritis in Papua New Guinea by active immunisation. Lancet 1979; 1: 227-9. 